\title{
A histopathological overview of ovarian lesions in Benin City, Nigeria: How common are the functional cysts?
}

Gerald Dafe Forae, Jonathan Umezulike Aligbe

Department of Pathology, University of Benin Teaching Hospital (UBTH), Benin City, Nigeria and Ashama Foundation Diagnostic Centre, Benin-City, Nigeria

Address for the Correspondence: Dr. G. D. Forae,

Department of Pathology, University of Benin Teaching Hospital (UBTH),

Benin-City, Nigeria.

E-mail: jforae2000@yahoo.com

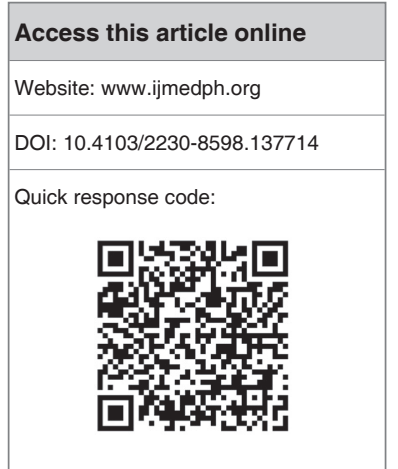

Aim: The aim of this study is to highlight the histopathological synopsis of ovarian lesions with emphasis on functional ovarian cysts and to compare our study with findings of other centers. Materials and Methods: Hematoxylin and eosin stainedslides of ovarian biopsies diagnosed at the Ashamas Foundation Diagnostic Centre, Benin City for 10 years were archived, scrutinized, and studied. Request forms were analyzed for clinical biodata and diagnosis, and data were analyzed with Statistical Package for Social Sciences (SPSS) version 17. Results: A total of 236 ovarian biopsies were reviewed. Of this, 121 (51.3\%) were nonneoplastic. Again $79(33.5 \%)$ were benign neoplastic tumors and $36(15.6 \%)$ were malignant tumors. Out of the 121 nonneoplastic (functional cysts) lesions, corpus luteal cyst was the most commonly encountered, constituting 41 (33.9\%). The peaks age incidence for nonneoplastic and benign neoplastic lesions occurred in the $3^{\text {rd }}$ decade. Two peaks age incidence was noted for malignant tumors $-5^{\text {th }}$ and $7^{\text {th }}$ decades. Germ cell tumor constituted the most common neoplastic ovarian tumor ( $n=59 ; 51.8 \%$ ) diagnosed. Conclusion: Functional ovarian cysts were the most commonly encountered ovarian lesions in our locality. The most common variety of functional cyst was corpus luteal cyst and hemorrhagic cyst with majority occurring in the reproductive age groups. Among the ovarian tumors, germ cell tumors were the most commonly seen.

Key words: Follicular cyst, functional cysts, luteal cysts, ovarian lesions

\section{INTRODUCTION}

Typically, ovarian masses consist of functional and pathological lesions. Functional lesions are mainly cystic and are the most commonly encountered lesions of this retroperitoneal organ. ${ }^{[1]}$ Functional cyst consist of mainly follicular and corpus luteal cysts. Majority of the functional cysts are simple cysts, while minority consists of complex cystic architecture. Studies have shown that $90 \%$ of these cysts are resolved spontaneously. ${ }^{[2]}$ These cyst are frequently seen in young female in their $2^{\text {nd }}$ decades due to failure of ovulation. However, fewer cases could also be seen in perimenopausal and postmenopausal women. ${ }^{[2,3]}$

Pathological lesions are predominantly tumors which could be benign, borderline, and malignant. Generally speaking, these tumors are rarer in childhood and adolescent age groups as studies have confirmed that only about $2 \%$ of ovarian tumors are seen in children. ${ }^{[2,3]}$ Most benign lesions of the ovary occur in childbearing age groups and are often cystic, while malignant tumors are more common in the elderly women. ${ }^{[4]}$

Globally, ovarian malignancy constitutes about $23 \%$ of all gynecological tumors with the highest fatality cases of incidence rate. ${ }^{[5,6]}$ In developing countries including Nigeria, there are low epidemiological statistics of ovarian cancers because most cases are underreported, in spite of the fact that it constitutes one of the most common gynecological problems locally and globally.

The aim of this study is to evaluate the histopathological patterns of ovarian lesions with emphasis on functional ovarian cysts, to compare our study to findings of other researchers, and to compare our study to findings of other centers in the world. 


\section{MATERIALS AND METHODS}

All ovarian biopsies received at the Ashamas Foundation Diagnostic Centre, Benin City, Edo State, Nigeria from January 2001 to December 2010 were studied. This center is the only private center in Benin City metropolis and Edo State offering histopathology services. Specimens were sent by gynecologists, surgeons, and general practitioners having private and public group practice in Benin City and its environs. The cases for the study were identified and extracted from the histopathology surgical daybooks of Ashamas Foundation Diagnostic Centre. Information regarding the age, clinical history, digital rectal examination, and clinical diagnosis was obtained. All specimens sent for histology were fixed in $10 \%$ formalin solution, processed with Histokinette automated tissue processor, paraffin embedded, and sectioned at 3-5 microns using the microtome machine before staining with hematoxylin and eosin. The results obtained were analyzed with respect to age, sex, and tumor type. Special stains; reticulin and periodic acid-Schiff stains were used where necessary. Ovarian lesions were classified according to the World Health Organization (WHO) histological classification.

Data obtained were analyzed using the Statistical Package for Social Sciences (SPSS) version 17 statistical package.

\section{RESULTS}

One hundred and twenty-one (51.3\%) of nonneoplastic (functional cysts) lesions, 79 (33.5\%) benign neoplastic tumors and $36(15.6 \%)$ malignant tumors giving a totality of 236 ovarian biopsies were reviewed at the Ashamas Foundation Diagnostic Centre. Out of the 121 nonneoplastic lesions, corpus luteal cyst was the most commonly encountered lesions constituting $41(33.9 \%)$. This was followed by hemorrhagic cyst (36,29.6\%). Others include follicular cyst and simple/ serous cyst constituting $20(16.5 \%)$ and 18 (14.9\%), respectively. Other less common nonneoplastic lesions were tuboovarian cyst and cortical cyst constituting two $(1.7 \%)$ each, while multicystic and polycystic disease accounted for one $(0.8 \%)$, respectively [See Figure 1].

Figure 2 has illustrated that the $3^{\text {rd }}$ decade was the most common peak age incidence for nonneoplastic $(n=43 ; 35.5 \%)$ and benign neoplastic lesions $(n=31 ; 39.2 \%)$, respectively. Two peak age $\left(5^{\text {th }}\right.$ and $\left.7^{\text {th }}\right)$ decades were noted for malignant tumors accounting for $(n=8 ; 22.2 \%)$ a piece out of the 36 cases. The $4^{\text {th }}$ decade was the $2^{\text {nd }}$ most common age distribution for nonneoplastic and benign neoplastic lesions accounting for $n=36(29.8 \%)$ and $n=23(29.1 \%)$, respectively.

Figure 3 show the classification of ovarian tumors according to the WHO classification of these tumors. The most common tumors among them was germ cell tumor constituting 59 (51.8\%) with peak age incidence at the $3^{\text {rd }}$ decade $(n=29 ; 49.2 \%)$ out of 59 cases. This is followed by surface epithelial tumors accounting for $33(28.9 \%)$ cases with peak age incidence in the $5^{\text {th }}$ decade of life accounting for $(n=9 ; 27.2 \%)$. Sex cord stromal tumor constituted $20(17.5 \%)$

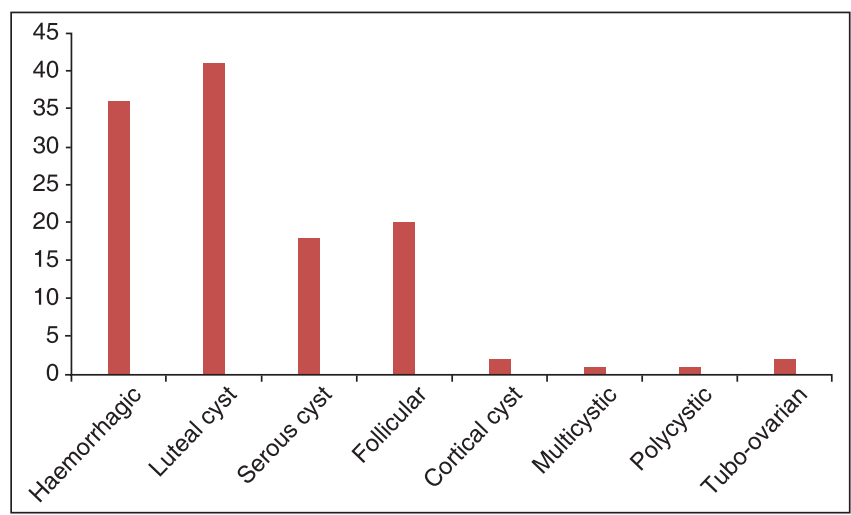

Figure 1: Frequency and patterns of functional ovarian cysts

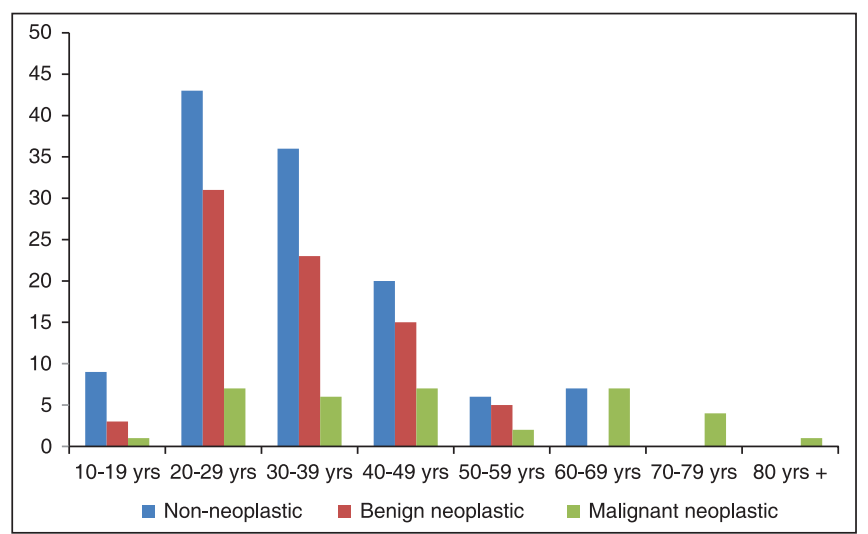

Figure 2: Age distributions and frequency of ovarian lesions

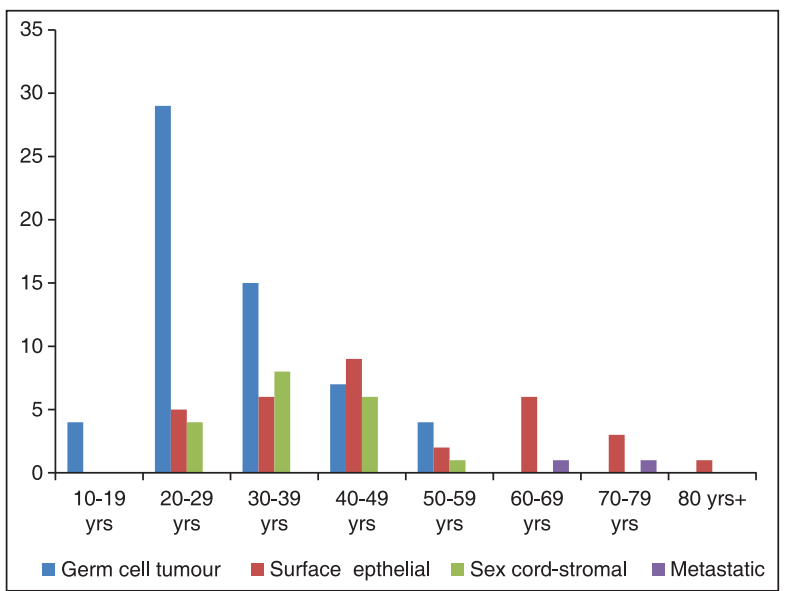

Figure 3: Distributions of histological types of ovarian tumors using the World Health Organization (WHO) criteria

with the peak age incidence in the $4^{\text {th }}$ decade $(n=8 ; 40.0 \%)$, while metastatic tumors to the ovary was relatively rare constituting only two cases seen in elderly patients.

\section{DISCUSSION}

In this study the most common ovarian lesion is the nonneoplastic lesion, of which vast majority are physiologic (functional cysts). This observation is similar to reports from Iran by Maliheh et al., 
where functional cysts was the most common encountered ovarian masses. ${ }^{[7,8]}$ Furthermore, similar report in Lahore has shown that functional cyst was the most encountered ovarian lesions. ${ }^{[8,9]}$ However, this is at variance with Ashraf et al.'s, reports where benign neoplastic tumors were the most commonly encountered ovarian lesions. However, these similar reports are in contrast to reports from Italy by Guerriero et al., where endometroma was the most common ovarian mass followed by the functional cysts. ${ }^{[9]}$ Again, in another similar study in Netherlands, de Kroon et al., observed that endometroma was the most commonly encountered lesion followed by dermoid cyst and functional cysts. ${ }^{[10]}$

Among the functional cysts in this study, corpus luteal cysts including hemorrhagic corpus luteum cysts was the most commonly encountered ovarian lesions. This is followed by follicular cysts. This finding is similar to studies done by Choi and Kim where corpus luteum cyst was the most commonly encountered ovarian lesions. ${ }^{[11]}$ Ashraf et al., also observed that corpus luteum cyst was the most frequently encountered functional cyst of the ovary. ${ }^{[12]}$ Hemorrhagic corpus luteum cysts is a corpus luteum cyst laden with hemorrhage. ${ }^{[13]}$ Nevertheless, other studies of functional cyst contradicts this report. Sumaira et al., in Pakistan has shown that follicular cyst was the most commonly encountered ovarian cysts. $^{[14]}$ Again our study is in contrast to conventional report where follicular cyst was the most commonly seen cysts of the ovary. Studies have found that majority of follicular cysts are asymptomatic and resolved spontaneously. ${ }^{[15,16]}$ The reason for this variation cannot be fully ascertain, but may be attributable to environmental, hormonal, and genetic influences.

Other commonly diagnosed cysts in our study include simple/serous cysts. Studies have also supported the fact that these cysts are also commonly reported by other researchers globally. ${ }^{[12,13,15,16]}$ Other functional ovarian cyst encountered in this study was relatively rare. This finding is similar to report of other researchers globally where literature documentations of the rarity of the cysts abound. ${ }^{[15,16]}$

In our study, the peak age incidence for both nonneoplastic and benign neoplastic lesions was seen in the $3^{\text {rd }}$ decade. This is similar to other reports where most of the benign ovarian lesions occur in women of reproductive age groups. ${ }^{[1,17]}$ In our study, ovarian malignancy cuts across all age groups and are seen in reproductive, perimenopausal, and postmenopausal women. Our study has supported the fact that ovarian neoplasm cuts across all age groups. However, majority of cases in the western world were seen in elderly postmenopausal women. ${ }^{[18]}$ The rationale for these variations could be attributed to poverty, short life expectancy, and ignorance in most developing countries including Nigeria.

Using the WHO criteria to classify ovarian tumors, it is conventionally known that surface epithelial was the most common lesion seen globally. Pilli et al., reported that ovarian epithelial surface tumors accounted for $70.9 \%$ of all ovarian tumors, this is followed by germ cell tumors constituting $21.2 \%$. Sex cord stromal tumors and metastatic tumors constituted 21.7 and $6.7 \%$, respectively. ${ }^{[19]}$
In our study, germ cell tumors were the most accosted ovarian tumors. However, the surface epithelial tumor was the second most encountered ovarian tumors in our locality. This report is in tandem with reports from Lagos by Onyiaorah et al., where germ cell tumor was the most common ovarian lesion followed by surface epithelial tumors. ${ }^{[20]}$ The reason for this variation is adducible to short life expectancy. The average life expectancy in Nigeria is 48 years. As a result, most women do not live long enough into the $8^{\text {th }}$ and $9^{\text {th }}$ decades to present with features of ovarian carcinomas. Once more, most of the cases go unreported as majority would seek alternative medication and spiritual healing.

In conclusion, functional ovarian cysts were the most commonly encountered ovarian lesions. The corpus luteal cyst including hemorrhagic cyst was far the most commonly encountered functional cyst in the ovary. Majority of this functional cyst occurred in the reproductive age groups. Among the ovarian tumors, germ cell tumors were the most commonly seen. This finding is in contrast to common findings where epithelial surface tumors were the most commonly encountered tumors globally.

\section{REFERENCES}

1. Kayastha S. Study of ovarian tumours in Nepal medical college Teaching Hospital. Nepal Med Coll J 2009;11:200-2.

2. Warner BW, Kuhn JC, Bar LL. Conservative management of large ovarian cysts in children: The value of serial pelvic ultrasonography. Surgery 1992;112:749-55.

3. Choudry A, Bangash N, Malik A, Choudry H. Adolescent ovarian tumours: A Clinico-pathological review of 15 cases. J Ayub Med Coll Abottabad 2008;20:18-21.

4. Pudasaini S, Lakhey M, Hirachad S, Akhter J, Thapa B. A study of ovarian in a tertiary hospital of Kathmandu Valley. Nepal Med Coll J 2011;13:39-41.

5. Merino MJ, Jaffe G. Age contrast in ovarian malignancy pathology. Cancer 1993;15:537-44.

6. Malik IA. A prospective study of clinic-pathological features of epithelial ovarian cancer in Pakistan. J Pak Med Assoc 2002;52:155-8.

7. Wasim T, Majrroh A, Saddiq S. Comparison of clinical presentation of benign and malignant ovarian tumours. J Pak Med Assoc 2009;59:18-21.

8. Maliheh A, Mohammed H, Nadereh M, Mehdi Y, Fazareh G, Mojgan E. Surgical histopathology of benign ovarian cysts: A multicentre study. Iran J Pathol 2010;5:132-6.

9. Guerriero S, Alcazar JL, Pascual MA, Ajossa S, Gerado M, Bargellini R, et al. Diagnosis of the most frequent benign ovarian cysts: Is ultrasonography accurate and reproducible? J Womens Health (Larchmt) 2009;18:519-27.

10. de Kroon CD, van der Sandt HA, van Houwelingen JC, Jansen FW. Sonographic assessment of non-malignant ovarian cysts: Does sonohistology exist? Hum Reprod 2004;19:2138-43.

11. Choi HJ, Kim SH, Kim SH, Kim HC, Park CM, Lee HJ, et al. Ruptured corpus luteal cysts: CT Findings. Korean J Radiol 2003;4:42-5.

12. Ashraf A, Shaikh AS, Ishfaq A, Akram A, Kamal F, Ahmad N. The relative frequency and histopathological patterns of ovarian masses. Biomed 2012;28:98-102.

13. Barel O, Smorgick N, Pansky M, Schneider D, Halperin R. Clinical and laboratory presentation of haemorrhagic corpus luteum. J Gynaecol Surg 2008;24:11-6.

14. Yasmin S, Yasmin A, Asif M. Clinicohistological pattern of ovarian tumours in Peshawar region. J Ayub Med Coll Abbottabad 2008;20:11-3.

15. Mackenna A, Fabres C, Alam V, Morales V. Clinical managementof functional ovarian cysts: A prospective and randomized study. Hum Reprod 2000;15:2567-9. 
16. Stenchever MA, Droegemueller W, HerbstAL, Mishell DR Jr. Comprehensive. Gynecology. $4^{\text {th }}$ edition. St. Louis, MO: Mosby; 2006: p. 901-10.

17. Mendal SK, Banyopadhyay R, Nag DR, Roychowdhury S, Mondal PK, Sinha SK. Histologic pattern, bilaterality and clinical evaluation of 957 ovarian neoplasms: A 10-year study of a tertiary hospital of eastern India. J Cancer Res Ther 2011;7:433-7.

18. Quirk JT, Natarajan N. Ovarian cancer incidence in the United States, 1992-1999. Gynaecol Oncol 2005;97:519-23.

19. Pilli GS, Suneeta KP, Dhaded AV, Yenni VV. Ovarian tumours: A study of 282 cases. J Indian Med Assoc 2002;100:420, 423-4, 447.
20. Onyiaorah IV, Anunobi CC, Banjo AA, Fatima AA, Nwankwo KC. Histopathological patterns of ovarian tumours seen in Lagos University Teaching Hospital: A ten year retrospective study. Nig Q J Hosp Med 2011;21:114-8.

How to cite this article: Forae GD, Aligbe JU. A histopathological overview of ovarian lesions in Benin City, Nigeria: How common are the functional cysts?. Int J Med Public Health 2014;4:265-8.

Source of Support: Nil, Conflict of Interest: None declared. 